\title{
The Effect of Antiretroviral Naïve HIV-1 Infection on the Ability of Natural Killer Cells to Produce IFN- $\gamma$ upon Exposure to Plasmodium falciparum-Infected Erythrocytes
}

\author{
Carole Stéphanie Sake ${ }^{a}$ b, e Loveline $\mathrm{Ngu}^{\mathrm{a}}$ e $\quad$ Georgia Ambada ${ }^{\mathrm{a}} \mathrm{d}$ \\ Jean Paul Chedjou ${ }^{d, g}$ Nadesh Njia Jules Colince Tchadji ${ }^{a}{ }^{d}$ \\ Abel Lissom ${ }^{a}$ d Thibau Flaurant Tchouangueu ${ }^{a, f} \quad$ Larissa Djukouo a, e \\ Ghislain Njambe ${ }^{a, d}$ Rosario Garcia ${ }^{i}$ Anna Gutierrez ${ }^{i, j}$ \\ Alain Bopda Waffoj Chae Gyu Park ${ }^{j}$ Wilfried Mbacham ${ }^{e, g, h}$ \\ François-Xavier Etoa ${ }^{b}$ c Godwin W. Nchinda ${ }^{a}$ \\ a Laboratory of Vaccinology/Biobanking, CIRCB, Messa Yaounde, b Department of \\ Microbiology, University of Yaoundé I, Yaoundé, 'University of Douala, Douala, \\ dDepartment of Animal Biology and Physiology, University of Yaoundé I, e Department of \\ Biochemistry, University of Yaoundé I, Yaoundé, ${ }^{f}$ Department of Biochemistry, University \\ of Dschang, Dschang, ${ }^{9}$ The Biotechnology Center, ${ }^{\mathrm{h}}$ The Department of Biochemistry and \\ Physiology, Faculty of Medicine, University of Yaounde I, Yaoundé, 'CSCB (Centre de santé \\ catholique de Bikop), Bikop, Cameroon; jDepartment of Biological Sciences, Alabama State \\ University, Montgomery, AL, USA; ${ }^{k}$ Laboratory of Immunology, Severance Biomedical \\ Science Institute, Yonsei University College of Medicine, Seoul, Korea
}

\section{What Is It about?}

Natural killer cells (NK) contribute to innate immunity to malaria either by direct lysis of Plasmodium falciparum-infected red blood cells (iRBC) or through IFN- $\gamma$ production after exposure to iRBC. However, HIV-1 infection depletes the immune system and can potentially impair NK cell-mediated innate immunity to $P$. falciparum infection. In this study we have demonstrated that the consequence of ARV naïve HIV-1 infection was to significantly reduce NK cell IFN- $\gamma$ production following exposure to iRBC.

\section{Keywords}

Malaria · Infected red blood cells · Natural killer cells · Antiretroviral naïve HIV infection

\section{Abstract}

Background: In sub-Saharan Africa, intense perennial Plasmodium species transmission coincides with areas of high prevalence of the human immunodeficiency virus type 1 (HIV) infection. This implies that antiretroviral naïve HIV-infected people living within these regions 
are repeatedly exposed to Plasmodium species infection and consequently malaria. Natural killer (NK) cells are known to contribute to malaria immunity through the production of IFN- $\gamma$ after exposure to Plasmodium falciparum-infected erythrocytes (infected red blood cells $[i R B C])$. However, in antiretroviral naïve HIV-1 infection, these functions could be impaired. In this study we assess the ability of NK cells from antiretroviral naïve HIV-1-infected people to respond to iRBC. Method: Magnetically sorted NK cells from antiretroviral naïve HIV-1-infected people were tested for their ability to respond to iRBC following in vitro coculture. NK cell IFN- $\gamma$ production after coculture was measured through multiparametric flow cytometry analysis. Results: Our data show a significant reduction $(p=0.03)$ in IFN- $\gamma$ production by NK cells from antiretroviral naïve HIV-1-infected people after coculture with iRBCs. This was in contrast to the NK cell response from healthy controls, which demonstrated elevated IFN- $\gamma$ production. NK cell IFN- $\gamma$ production from untreated HIV-1-infected participants correlated inversely with the viral load $(r=-0.5, p=0.02)$ and positively with total helper CD4 ${ }^{+} \mathrm{T}$-cell count $(r=0.4, p=0.04)$. Thus, antiretroviral naïve HIV-1 infection can dampen NK cell-mediated immunity to $P$. falciparum infection in malaria-intense regions. This could in effect escalate morbidity and mortality in people chronically infected with HIV-1.

(C) 2017 The Author(s)

Published by S. Karger AG, Basel

\section{Introduction}

In sub-Saharan Africa, regions of intense perennial malaria coincide with zones of high prevalence of HIV infection. Sub-Saharan Africa alone accounts for close to $70 \%$ of the global HIV infection [1], concurrent with well over 214 million malaria cases in 2015 [2]. The morbidity and mortality arising from the combined effect of these 2 infections is thus enormous [3]. HIV-1 infection maintains the immune system in a sustained state of activation and impairs adaptive immunity through selective depletion of helper CD4 T cells [4-6]. Intense perennial Plasmodium species transmission implies that antiretroviral naïve HIVinfected people living within these regions are repeatedly exposed to malaria, which could potentially escalate inflammation and consequent HIV disease progression. In the absence of a functional adaptive immune response due to HIV infection [6, 7], natural killer (NK) cells could play a prominent role in innate immune activities against opportunistic infections. NK cells comprise $5-20 \%$ of human peripheral blood mononuclear cells $[8,9]$. They can spontaneously sense and lyse virus-infected cells $[8,10,11]$ in nonspecific contact and a nonphagocytic process that does not require prior sensitization to antigen [12]. They also produce cytokines and chemokines for immunoregulatory activity against a variety of allogeneic targets $[13,14]$. Human NK cells were previously divided into 2 major subsets according to phenotypic and functional differences, namely CD56 $6^{\text {bright }} / \mathrm{CD} 16^{-} \mathrm{NK}$ cells, which are the minor subset in peripheral blood $(10 \%$ of total $\mathrm{NK})$ and have predominantly immunoregulatory properties and a potent cytokine (mainly IFN- $\gamma$ )-producing capacity $[15,16]$, and CD56 $\mathrm{dim} /$ $\mathrm{CD}^{+} 6^{+}$, which represent $90 \%$ of total NK cells and secrete low levels of cytokines and have a predominantly cytotoxic function [8]. Currently, 3 subtypes of NK are recognized [17]: CD56 $6^{\mathrm{dim}} / \mathrm{CD} 16^{+}, \mathrm{CD} 56^{\text {bright }} / \mathrm{CD} 16^{+/-}$, and $\mathrm{CD} 56^{-} / \mathrm{CD} 16^{+} \mathrm{NK}$ cells. In addition to their activity against tumors and virus-infected cells, NK cells are capable of responding to protozoan pathogens including plasmodia. Although an innate response to Plasmodium species is often overlooked, human NK cells upon exposure to Plasmodium falciparum-infected erythrocytes respond by producing IFN- $\gamma$, which could be vital in immunity to malaria [18-20]. In addition to IFN- $\gamma$, NK cells have also been reported to produce granzyme B (GB) in response to Plasmodium species [18]. Moreover, NK cells have also been reported to directly lyse infected red blood cells (iRBC) [21]. Thus, the importance of NK cells in the control of early parasitaemia 
has been demonstrated in several reports [21, 22]. However, in antiretroviral naïve HIV-1 infection, several functions of NK cells including cytokine production and cytolysis could be affected.

In this study we assess the ability of NK cells from antiretroviral naïve HIV-infected people to respond to iRBC. Our hypothesis is that untreated HIV infection promotes immune depletion, which as a consequence also dampens NK-mediated innate immune responses to malaria. We show that NK cell-mediated immune response to malaria is significantly impaired in antiretroviral naïve HIV-infected people.

\section{Methods}

\section{Study Population}

Twenty-one antiretroviral naïve HIV-infected participants and 18 HIV-negative controls aged between 21 and 65 years were included in the study. Participants with coinfection (including malaria, dengue, and hepatitis B and C) and pregnant women were excluded from the study. In addition, 4 HIV-negative/malaria-positive adults were recruited for iRBC enrichment. All participants were members of the Centre International de Reference Chantal Biya (CIRCB) AFRODEC cohort. The AFRODEC cohort is a cohort of antiretroviral naïve HIVinfected people who have been monitored in CIRCB since 2011.

\section{Ethical Considerations}

This study was approved by the National Ethical Committee of Cameroon with administrative authorization No. 2015/08/631/CE/CNERSH/SP. Enrolment was voluntary and each participant gave a written informed consent.

\section{Peripheral Blood Mononuclear Cell Separation}

Twenty milliliters of venous blood was obtained from each participant consisting of 21 antiretroviral naïve HIV-infected and 18 seronegative donors by trained clinicians in the CIRCB medical section. Venous blood was drawn in EDTA tubes. Peripheral blood mononuclear cells were separated by density gradient centrifugation (using Ficoll-Hypaque) from whole blood and washed twice in cold $1 \times \mathrm{PBS}\left(1,200 \mathrm{rpm}\right.$ at $4{ }^{\circ} \mathrm{C}$ for $\left.10 \mathrm{~min}\right)$. Peripheral blood mononuclear cells were counted after the first wash and used for NK cell purification using magnetic sorting.

\section{Malaria Diagnosis}

Blood samples were obtained from 4 malaria-positive donors. A malaria rapid diagnostic test was done according to the manufacturer's instructions (SD Bioline). In addition, thick peripheral blood films were stained with Giemsa and examined using a microscope following standard quality-controlled procedures. The parasite load is expressed as the number of asexual forms of $P$. falciparum per microliter of blood.

\section{P. falciparum-Infected Red Blood Cell Enrichment and Culture}

P. falciparum-infected blood samples were transferred into Eppendorf tubes and centrifuged at $5,000 \mathrm{~g}$ for $5 \mathrm{~min}$. The supernatant was removed and the pellet containing the RBC was washed twice at $3,000 \mathrm{~g}$ for $5 \mathrm{~min}$ with an equal volume of malaria culture medium (10.43 g RPMI 1640 powder supplemented with 1 M HEPES, $1.6 \mathrm{~mL}$ of $7.5 \% \mathrm{NaHCO}_{3}, 5 \mathrm{~g}$ of 20\% AlbuMAX II, $25 \mathrm{mg}$ ampicillin, $1 \mathrm{~L}$ distilled water) as described previously [23, 24]. P. falciparum-infected blood was cultured for $72 \mathrm{~h}$ at $37^{\circ} \mathrm{C}$ in an anaerobic jar. Next they were harvested at late-stage schizonts and then purified by Ficoll gradient centrifugation accord- 
ing to a modified protocol of Fernandez et al. [25]. Briefly, cultures were spun at 5,000 $\mathrm{g}$ for $5 \mathrm{~min}$, and then the cells were washed 3 times in malaria culture medium. The number of schizonts was determined for each malaria-infected culture and expressed as schizonts per $\mu \mathrm{L}$. Then iRBC were normalized to have $1 \times 10^{5}$ iRBC per $\mathrm{mL}$ of medium for each sample according to protocols adapted from Fernandez et al. [25]. In addition, malaria-negative red blood cells (uRBC) were similarly enriched from 4 negative donors.

\section{NK Cell Purification}

To set up in vitro NK cells and iRBC coculture, human NK cells were purified using magnetic microbeads according to the manufacturer's instructions (Miltenyi Biotec, Germany). Briefly, NK cells were magnetically sorted from peripheral blood mononuclear cells through negative selection according to the manufacturer's instructions.

Purified NK cells (with a mean purity of $92.3 \%$ ) from both antiretroviral naïve HIV1-infected people and healthy controls were washed twice in RPMI 1640 (Lonza), and resuspended at a concentration of $1 \times 10^{6}$ cells/mL in complete culture medium (RPMI 1640 supplemented with $2 \mathrm{mM} \mathrm{L-glutamine,} 10 \% \mathrm{FBS}$, 1\% pen/strep $(100 \mathrm{U} / \mathrm{mL}$ penicillin, $100 \mathrm{~g} /$ mL streptomycin).

\section{Human NK Cell Coculture with iRBC}

Purified NK cells were mixed with RBC in round-bottom 96-well plates and cocultured either with the enriched iRBC or $u R B C$ at $37^{\circ} \mathrm{C}$ in $5 \% \mathrm{CO}_{2}$ for $24 \mathrm{~h}$ at a ratio of $1: 3$. Wells with uninfected erythrocytes (uRBC) were used as controls. Brefeldin A (to a final concentration of $10 \mu \mathrm{g} / \mathrm{mL}$; Sigma-Aldrich) was added to cells for the last $4 \mathrm{~h}$ of incubation. Samples were harvested for multiparametric flow cytometry analysis of NK cell IFN- $\gamma$ production as well as GB and perforin expression.

\section{Cell Surface and Intracellular Staining for Flow Cytometry}

Following the $24 \mathrm{~h}$ of incubation, cells were transferred into a $96 \mathrm{~V}$-bottom plate. After $\mathrm{F} c \gamma$ receptor blocking, the cells were washed twice with FACS buffer (PBS 1×, 2\% FBS, 1\% EDTA), stained with fluorochrome-conjugated antibodies to CD56 (CD56-APC- R-700), CD16 (CD16- PECF-594), CD3 (CD3-FITC), and LIVE/DEAD stain for 20 min at $4{ }^{\circ} \mathrm{C}$. Cells were then washed, fixed (Cytofix/Cytoperm; BD Biosciences), permeabilized with Permwash, and stained intracellularly for IFN- $\gamma$ (IFN- $\gamma-$ PE), perforin (perforin - PerCP cy5.5), and GB (Granzyme B - BV510) for 20 min at room temperature in the dark. All antibodies were from eBioscience. The cells were suspended in $400 \mu \mathrm{L}$ of FACS buffer and samples were acquired either with a FACSCanto II flow cytometer or Fortessa X5 (BD Biosciences). We used FlowJo (Tree Star) for data analysis.

\section{Statistical Analysis}

All statistical analyses were performed using Prism (GraphPad 5). Nonparametric tests (Spearman) were used in all analyses; $p<0.05$ was considered statistically significant.

\section{Results}

\section{Study Population}

A total of 21 antiretroviral naïve HIV-positive and 18 HIV-negative people were recruited for this study. HIV-positive participants included 8 males and 15 females, whereas the HIVnegative volunteers consisted of 6 males and 12 females. The median age for the HIV-positive individuals was 43 years (range: 32-59) and for HIV-negative controls it was 28.5 years 
Table 1. Antiretroviral naïve HIV-1-infected participant's clinical characteristics

\begin{tabular}{llllll}
\hline & $\begin{array}{l}\text { Individuals, } \\
n\end{array}$ & Gender & $\begin{array}{l}\text { Age, years } \\
\text { (range) }\end{array}$ & $\begin{array}{l}\text { Helper CD4 T-cell count, } \\
\text { cells } / \mathrm{mm}^{3} \text { (range) }\end{array}$ & $\begin{array}{l}\text { Viral load } \\
- \text { RNA copies/mL (range) } \\
-\log _{10} \text { RNA copies } / \mathrm{mL}(\mathrm{range})\end{array}$ \\
\hline $\mathrm{HIV}^{+}$group & 21 & $\begin{array}{c}8 \text { males } \\
13 \text { females }\end{array}$ & $43(32-59)$ & $468(55-959)$ & $3,058(40-10,004,094)^{1}$ \\
\hline HIV $^{-}$group & 18 & $\begin{array}{c}7 \text { males } \\
11 \text { females }\end{array}$ & $28.5(18-46)$ & $991.5(507-1,400)$ & \\
\hline
\end{tabular}

${ }^{1}$ Range (minimum-maximum).

(range: 18-46) (Table 1). The median helper CD4 T-cell count for the HIV-positive participants was 468 (range: 55-959) and for the HIV-negative participants it was 991 (range: 507-1,400) (Table 1). As expected, there was a significant difference $(p<0.05)$ between the median of the helper CD4 T-cell count of HIV-positive and -negative participants.

\section{NK Cell Purification and Subpopulation Expression}

Lymphocytes were defined from side scatter versus forward scatter gate (1) (Fig. 1a). Negative NK and dead cells were excluded from the lymphocyte population using a dumping channel (CD19, CD20, CD14, CD3) and live-dead as shown on Figure 1a (2). Purified NK cells were then gated and the NK cell subpopulations were defined using CD56 versus CD 16 gate (3). NK cell subpopulations were identified as $\mathrm{CD}^{+} 6^{+} / \mathrm{CD} 16^{-}, \mathrm{CD}^{+} 6^{+} / \mathrm{CD} 16^{+}$, and $\mathrm{CD}^{-} 6^{-} /$ CD $16^{+}$. The purity percentage of the NK cells ranged from 90 to $95.2 \%$ with a mean of $92 \pm$ 3\% (Fig. 1b (2)).

As shown in Figure 1c, there was no significant difference between total NK cells of HIVpositive and -negative participants. Even when we compared the NK cell subpopulations, there were no significant differences between HIV-positive and -negative participants for the $\mathrm{CD}^{2} 6^{+} / \mathrm{CD} 16^{-}$and $\mathrm{CD} 56^{+} / \mathrm{CD} 16^{+}$subpopulations, whereas the $\mathrm{CD} 56^{-} / \mathrm{CD} 16^{+} \mathrm{NK}$ cell subpopulation significantly increased $(p=0.02)$ in HIV-positive participants as shown in Figure 1d.

\section{NK Cells Coculture with iRBC Induced IFN- $\gamma$ Production}

We tested the ability of NK cells to produce IFN- $\gamma$ upon exposure to $P$. falciparum-infected RBC. NK cell IFN- $\gamma$ production was evaluated under 3 different conditions: (i) NK cells alone, (ii) NK cells after coculture with uRBC, and (iii) NK cells after coculture with iRBC. Following in vitro coculture and multiparametric flow cytometry analysis, NK cells were identified in FlowJo analysis using the gating strategy shown in Figure $2 \mathrm{a}$. NK cell IFN- $\gamma$ production was compared before and after coculture with the differentially treated RBC. In the absence of RBC (NK alone), little or low levels IFN- $\gamma$ production was observed. Following coculture with uRBC, a significant increase ( $p=0.01, p=0.05)$ in NK cell IFN- $\gamma$ production was observed with respect to NK cells cultured alone (Fig. 2b). Similarly, when NK cell coculture with uRBC was compared to coculture with iRBC, a significant increase ( $p=0.05, p=0.03)$ in NK cell IFN- $\gamma$ production was observed (Fig. 2a). Therefore, iRBC were necessary in the coculture for the augmented NK cell IFN- $\gamma$ production.

The effect of antiretroviral naïve HIV infection was a significant reduction in NK cell IFN- $\gamma$ production after coculture with iRBC $(p=0.03)$ as shown in Figure 2c.

In Figure 2c, a significant decrease $(p=0.03)$ in NK cell IFN- $\gamma$ production is observed when antiretroviral naïve HIV-infected participants (HIV positive) are compared with HIV- 
(c) 2017 The Author(s). Published by S. Karger AG, Basel www.karger.com/bmh

Sake et al.: The Effect of Antiretroviral Naïve HIV-1 Infection on the Ability of NK Cells to Produce IFN- $\gamma$ upon Exposure to $P$. falciparum-Infected Erythrocytes

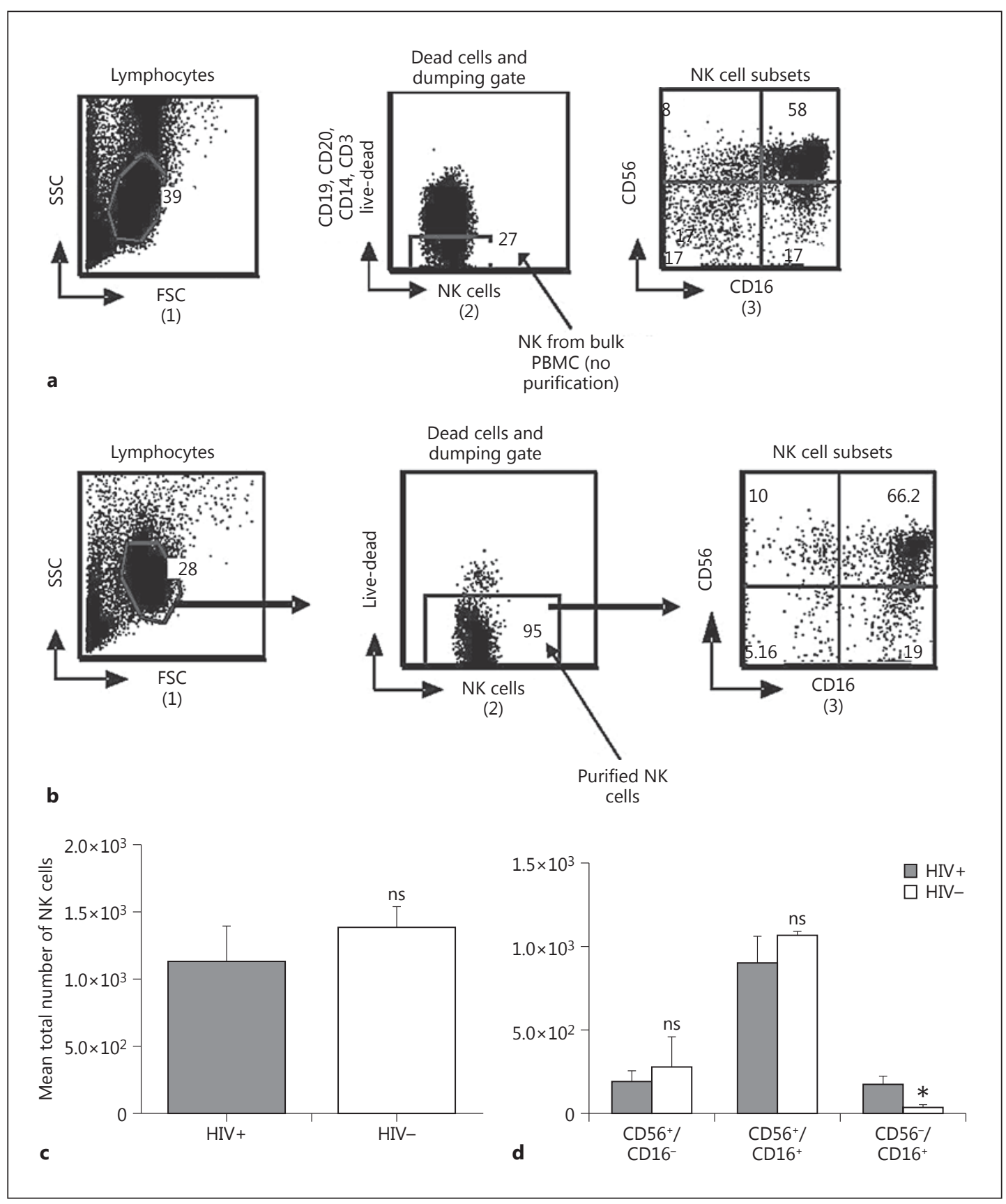

Fig. 1. a Gating schema for bulk NK cells. As shown in 1, lymphocytes were gated from cells debris using side scatter (SSC) versus forward scatter (FSC). NK cells were selected out from a dumping channel consisting of B cells, T cells, monocyte, and dead cells (2). The NK cells were then displayed according to the expression of CD56 and CD16 (3). b Gating schema for purified NK cells: magnetic sorted NK cells were similarly gated and NK cells displayed as described in a. Magnetic purification resulted in a significant increase in the total NK subset and ranged from 90 to $95 \%$. c Comparison of total NK cells. d CD56 $6^{+} / \mathrm{CD}_{16}, \mathrm{CD}^{-} 6^{+} / \mathrm{CD}_{16}{ }^{+}$, and $\mathrm{CD}^{-} 6^{-} / \mathrm{CD} 16^{+} \mathrm{NK}$ cell subsets were identified and compared between HIV-positive (HIV+) and HIV-negative (HIV-) participants. A significant increase was observed in HIV+ for CD56 ${ }^{-} / C_{1} 16^{+}$expression. PBMC, peripheral blood mononuclear cells. ${ }^{*} p=0.02$. ns, not significant $(p<0.05)$. 
Sake et al.: The Effect of Antiretroviral Naiive HIV-1 Infection on the Ability of NK Cells to Produce IFN- $\gamma$ upon Exposure to $P$. falciparum-Infected Erythrocytes

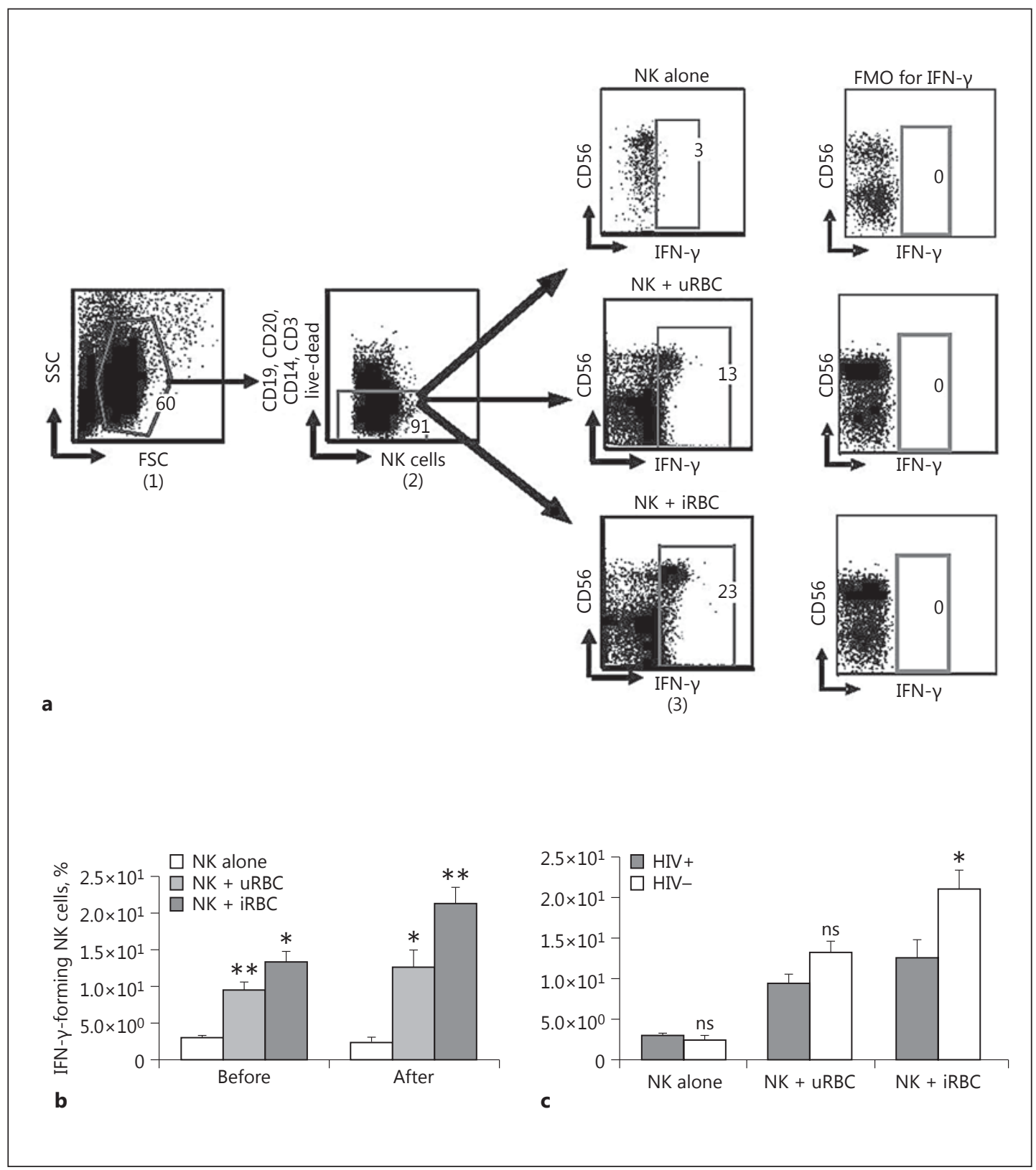

Fig. 2. NK cell IFN- $\gamma$ production following coculture with either Plasmodium falciparum-infected RBC or uRBC red blood cells. Purified NK cells were cocultured either with enriched red blood cells or uRBC (1:3) for $24 \mathrm{~h}$ and stained for flow cytometric analysis. NK cell IFN- $\gamma$ production before and after coculture was measured using multiparametric flow cytometric analysis. a Gating schema for purified NK cell IFN- $\gamma$ production coculture with iRBC. The strategy shows NK cell IFN- $\gamma$ production before and after coculture with either iRBC or uRBC. Lymphocytes were defined from side scatter (SSC) versus forward scatter (FSC) gate (1). NK cells are identified as live lymphocytes that are CD3, CD14, CD20, and CD19 negative but expressing CD56 (2). CD56 versus IFN- $\gamma$ gate (3) was used to define $\mathrm{CD}^{2} 6^{+} / \mathrm{IFN}-\gamma^{+}$cells (NK cells producing IFN- $\gamma$ ). The resulting data were analyzed and depicted for the overall populations, showing a comparison before and after coculture (b) and a comparison of NK cell IFN- $\gamma$ production between the HIV+ and HIV-groups (c). The mean \pm SD of 5 different repeat experiments are shown. A Mann-Whitney test was used to compare medians $(p<$ 0.05). FMO, Fluorochrome Minus One. ${ }^{*} p<0.05$. ${ }^{* *} p<0.01$. ns, not significant $(p>0.05)$. 
Sake et al.: The Effect of Antiretroviral Naïve HIV-1 Infection on the Ability of NK Cells to Produce IFN- $\gamma$ upon Exposure to $P$. falciparum-Infected Erythrocytes

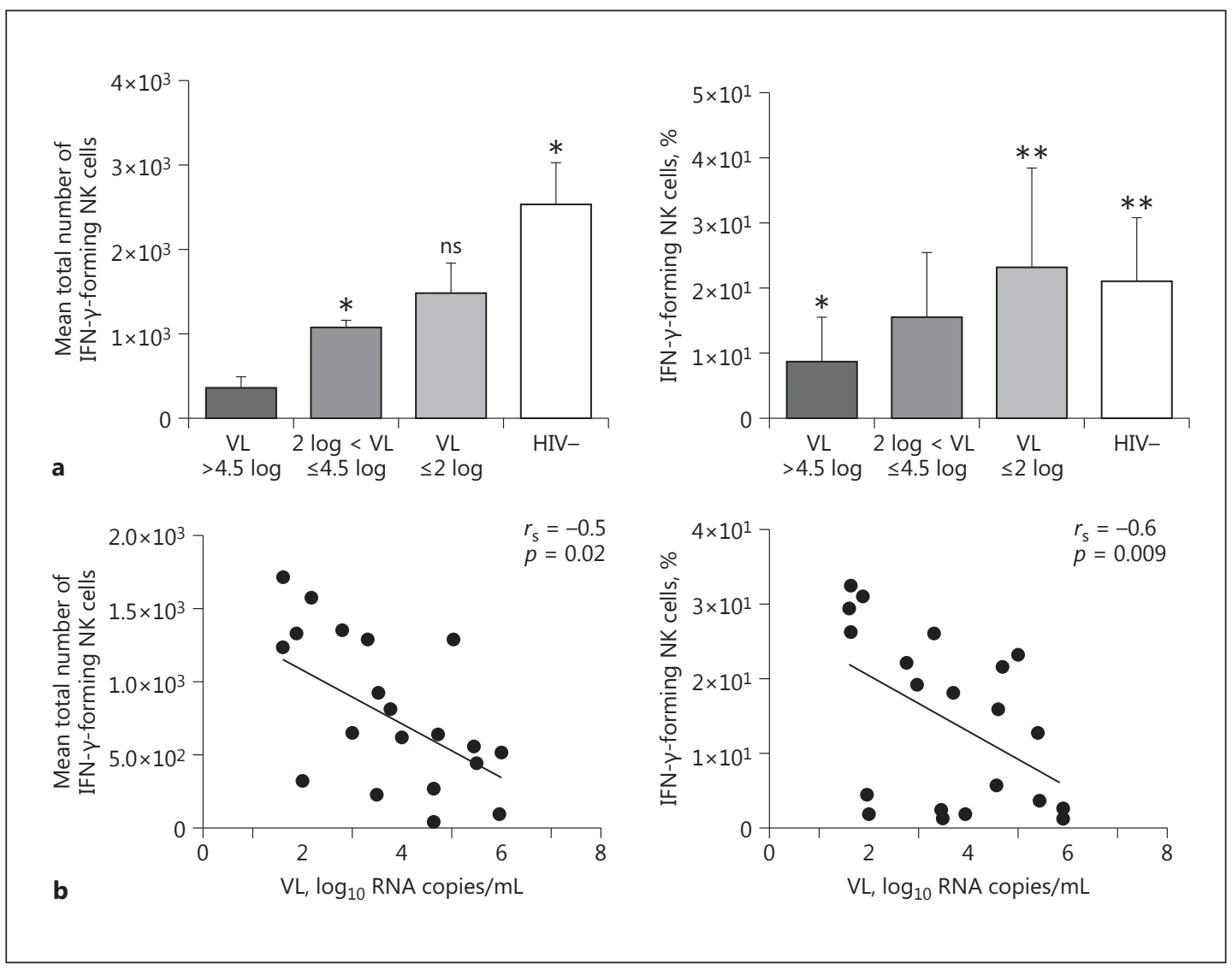

Fig. 3. Impact of HIV plasmatic VL on NK cell IFN- $\gamma$ production after coculture with iRBC. a Antiretroviral naïve HIV-1-infected people were classified into 3 groups according to VL level: VL $<2 \log , 2 \log <$ VL $\leq 4.5$ $\log$, and VL $>4.5$ log. Quantification of IFN- $\gamma$ produced by NK cells using multiparametric flow cytometric analysis in each group is shown; a Mann-Whitney test was used to compare the means between groups $(p<$ 0.05). $* p<0.05$. ns, not significant $(p>0.05)$. b Inverse correlation between NK cell IFN- $\gamma$ production and plasmatic VL.

negative donors, following a 24-h coculture with iRBC (Fig. 2c). In contrast, NK cells from HIV-negative participants demonstrated elevated IFN- $\gamma$ production upon exposure to iRBC (Fig. 2c). In the absence of RBC (NK alone) and in the presence of $u R B C$, no significant difference was observed between the NK cells of both HIV-positive and -negative participants in their ability to produce IFN- $\gamma$ (Fig. 2c).

\section{Impact of HIV Plasmatic Viral Load on NK Cell IFN- $\gamma$ Production}

Since there was a significant reduction in NK cell IFN- $\gamma$ production after coculture of HIV-1-infected participant NK cells with iRBC, we tested whether plasmatic RNA viral load (VL) was implicated. Firstly, antiretroviral naïve HIV-1-infected participants from the CIRCB AFRODEC cohort were grouped according to their VL into 3 main categories: (i) VL $\leq 2 \log _{10}$, (ii) $2 \log _{10}<$ VL $\leq 4.5 \log _{10}$, and (iii) VL $>4.5 \log _{10}$ (Fig. 3a). Secondly, a correlation was determined between NK cell IFN- $\gamma$ production following coculture with iRBC and the 3 groupings of plasmatic RNA VL. As shown in Figure 3a, NK cell IFN- $\gamma$ production decreased with increasing VL. Thus, after coculture with $\mathrm{RBBC}$, there was a negative correlation between plasmatic VL and IFN- $\gamma$-forming NK cell count $\left(r_{\mathrm{s}}=-0.5, p=0.02\right)$. The same observation was done between VL and percentage of IFN- $\gamma$ produced $\left(r_{\mathrm{s}}=-0.6, p=0.009\right.$ ) (Fig. 3b). 


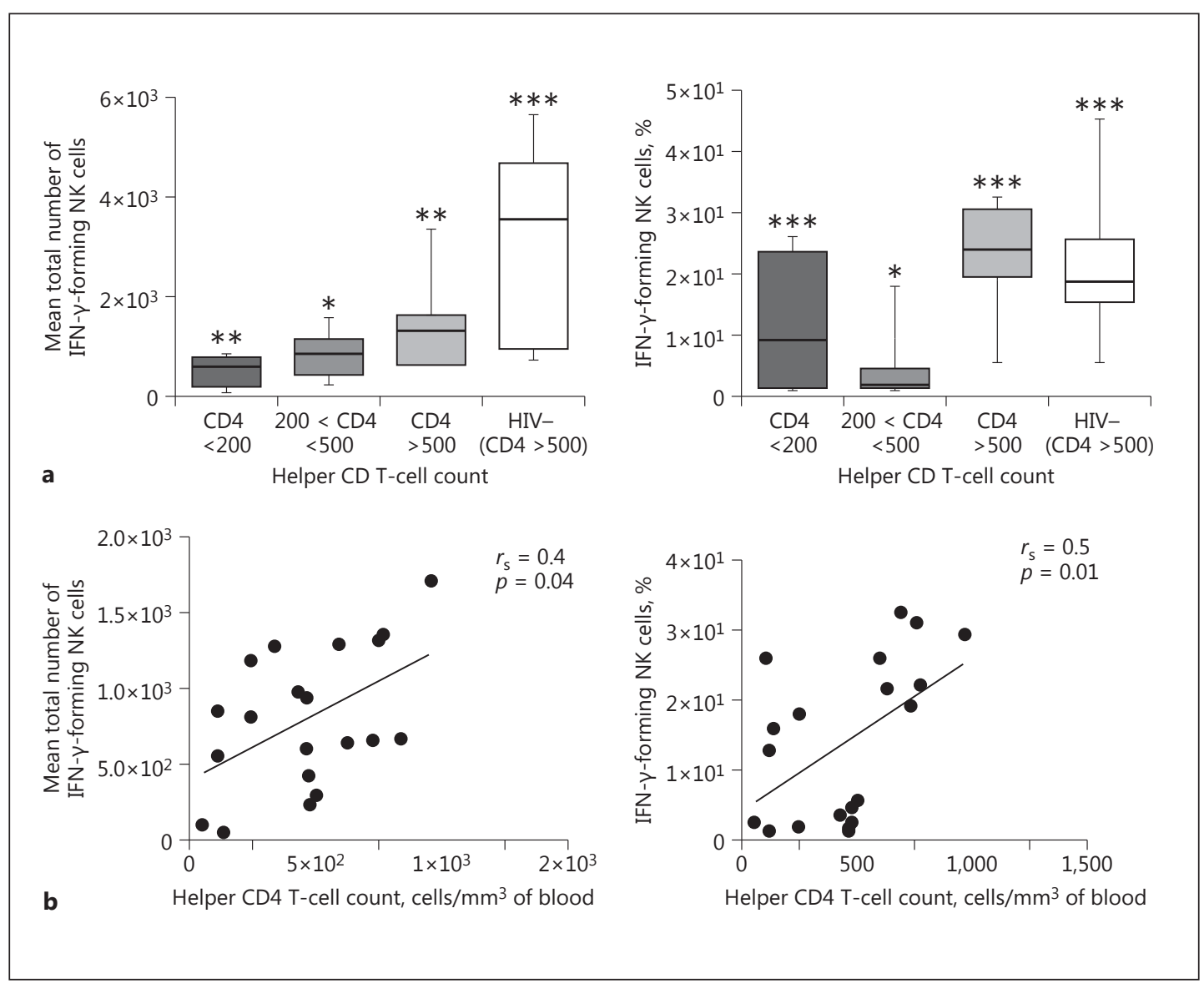

Fig. 4. Relation between the helper CD4 T-cell count and NK cell IFN- $\gamma$ production after coculture with iRBC. a Antiretroviral naïve HIV-1-infected people were grouped according to helper CD4 T-cell count (CD4 count): CD4 $<200,200<$ CD4 $\leq 500$, and CD4 $>500$. NK cell IFN- $\gamma$ production in each group is shown; a Mann-Whitney test was used to compare means between groups ( $p<0.05$ considered as significant). ${ }^{*}$ Expresses a significant difference. ${ }^{* *} p<0.01$. ${ }^{* * *} p<0.001$. Groups with similar symbols express no significant difference. On the other hand groups with different symbols indicate a significant difference. $\mathbf{b}$ Positive correlation between NK cell IFN- $\gamma$ production and CD4 count.

\section{Relation between Helper CD4 T-Cell Count and NK Cell IFN- $\gamma$ Production}

Antiretroviral naïve HIV-1-positive people were grouped according to their helper CD4 T-cell count (cells $/ \mathrm{mm}^{3}$ of blood) following the WHO categorization. Taking 3 groupings consisting of (i) HIV-positive participants with $\mathrm{CD} 4^{+}$T-cell counts less than 200, (ii) CD4 between 200 and 500, and (iii) CD4 more than 500, we measured the correlation between NK cell IFN- $\gamma$ production and CD4+ T-cell values. As shown in Figure 4a, NK cell IFN- $\gamma$ production decreased significantly only when CD4 T cells were less than 200. Again, as stated above, there were significant differences ( $p=0.03$ ) between HIV-positive and -negative participants with respect to NK cell IFN- $\gamma$ production. In Figure $4 \mathrm{~b}$, a positive correlation between NK cell IFN- $\gamma$ production and CD 4 count is shown with a Spearman correlation coefficient $\left(r_{\mathrm{s}}\right)$ of 0.4 $(p=0.04)$. Even when comparing the percentage of IFN $-\gamma$ and CD 4 count, there was a positive correlation $\left(r_{\mathrm{s}}=0.5, p=0.01\right)$. 
Sake et al.: The Effect of Antiretroviral Naïve HIV-1 Infection on the Ability of NK Cells to Produce IFN- $\gamma$ upon Exposure to P. falciparum-Infected Erythrocytes

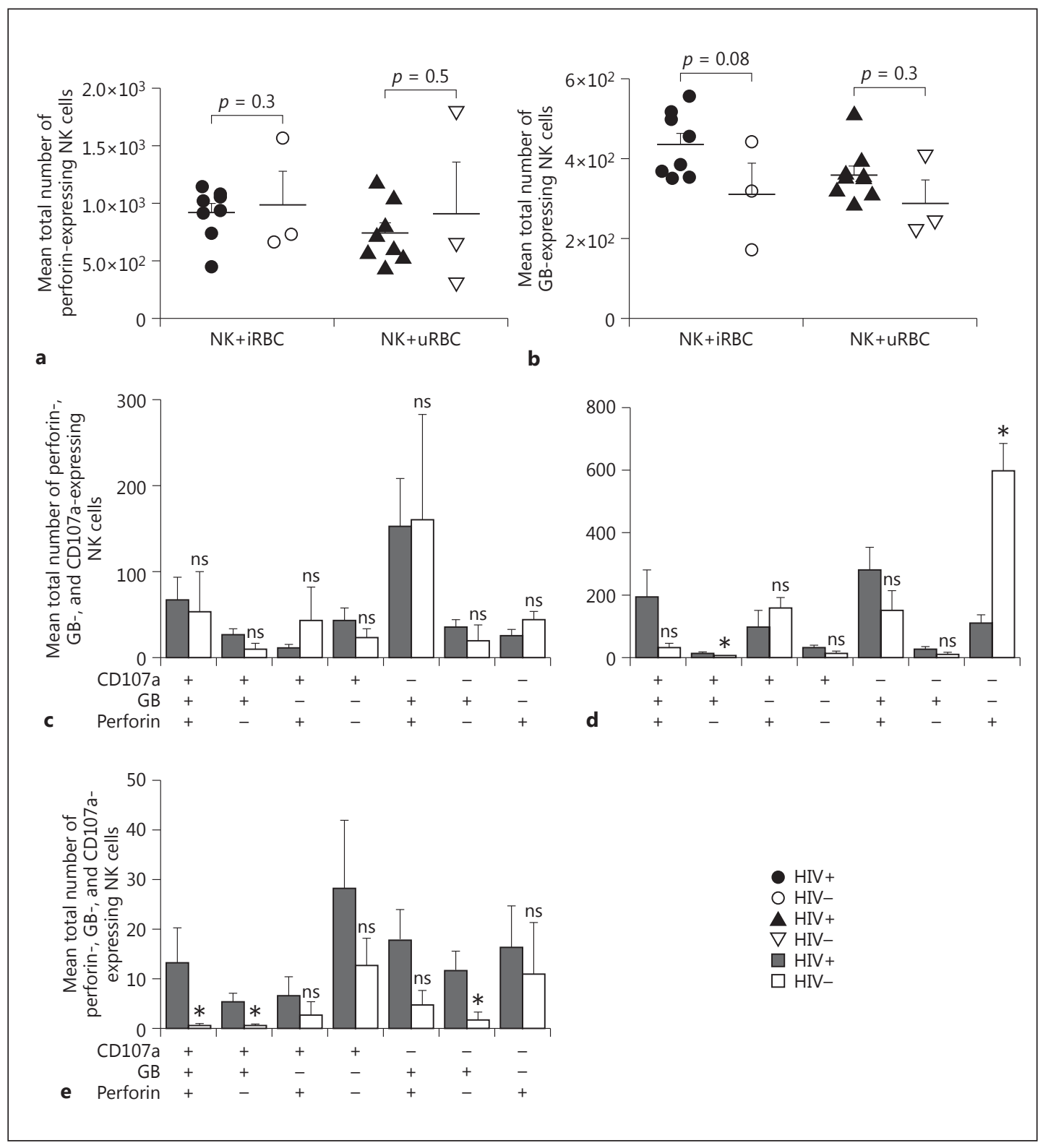

Fig. 5. NK cell perforin and GB production before and after coculture either with Plasmodium-infected RBC or URBC red blood cells. a Comparison between HIV+ and HIV-; NK cell perforin expression after coculture either with iRBC or uRBC. NK cell perforin expression was determined and represented as the mean \pm SD $(p<0.05$ considered as significant). $\mathbf{b}$ NK cell GB response was also determined and represented as the mean \pm SD. Comparison between the HIV+ and HIV-controls groups was done using a Mann-Whitney test $(p<0.05$ considered as significant). c-e Expression of perforin, GB, and CD107a, respectively, in CD56 ${ }^{+} / \mathrm{CD}_{16}{ }^{-}, \mathrm{CD}^{2} 6^{+} /$ $\mathrm{CD}_{16} 6^{+}$, and $\mathrm{CD}^{-} 6^{-} / \mathrm{CD} 16^{+} \mathrm{NK}$ cells subsets prior to coculture. Single and multiple combinations were done (perforin+, perforin+/GB+, perforin+/GB+/ CD107a+, etc.). The presence of each protease is represented by $(+)$ and the absence by $(-)$. Results are presented as means \pm SD and a Mann-Whitney test was use to compare distributions ( $p<0.05$ considered as significant). 


\section{NK Cell Perforin and GB Expression When Exposed to iRBC}

We next evaluated the cytotoxic potential of human NK cells in response to iRBC. Our hypothesis was that antiretroviral naïve HIV-1 infection could dampen NK cells' cytotoxic activity by limiting their potential to lyse iRBC. Thus, samples of the present study were also tested for cytotoxic proteases, GB, and perforin production (Fig. 5). Having shown that cytolytic protein (perforin) is expressed more (no significant difference, $p=0.3$ ) in HIV-negative people when compared to HIV-positive people before coculture with RBC (Fig. 5), we assessed the ability of NK cells to produce perforin in the presence of iRBC. NK cells producing perforin were identified by flow cytometric analysis and defined as $\mathrm{CD}^{-} 9^{-} / \mathrm{CD}^{-} 0^{-} / \mathrm{CD}^{-} 4^{-} / \mathrm{CD}^{-} /$ ${\mathrm{CD} 56^{+} / \text {perforin }}^{+}$live cells. HIV-positive individuals showed a slight decrease in NK cell perforin production after coculture with iRBC, but the difference was not significant $(p=0.3)$ when compared to HIV-negative controls (Fig. 5a).

NK cells' GB production was similarly monitored. As shown in Figure 5a, after contact with iRBC, an elevated but nonsignificant ( $p=0.08$ ) GB production was observed in HIVpositive participants vis-à-vis HIV-negative controls. A similar observation was made with $\operatorname{uRBC}(p=0.3)$.

In the absence of RBC, levels of perforin, GB, and CD107a showed no significant differences between HIV-positive and -negative participants in the $\mathrm{CD} 56^{+} / \mathrm{CD} 16^{-} \mathrm{NK}$ cell subset (Fig. 5c). In CD56 $6^{+} \mathrm{CD} 16^{+} \mathrm{NK}$ cells, expression of perforin was significantly ( $p=0.01$ ) low in HIV-positive participants compared to HIV-negative participants, whereas NKcells expressing GB plus CD107a showed a significant ( $p=0.03$ ) increase in HIV-positive participants (Fig. $5 d$ ). In Figure 5e, the $\mathrm{CD}^{2} 6^{-} / \mathrm{CD} 16^{+} \mathrm{NK}$ cell subset of HIV-positive participants showed significantly higher levels of $\mathrm{GB}^{+} / \mathrm{CD} 107 \mathrm{a}^{+}$when compared to HIV-negative participants. Interestingly, $\mathrm{CD}^{-} 6^{-} / \mathrm{CD} 16^{+} \mathrm{NK}$ cells simultaneously producing perforin, $\mathrm{GB}$, and CD107a showed significantly ( $p=0.03$ ) higher levels in HIV-positive participants in comparison to those who were HIV negative. Thus, antiretroviral naïve HIV infection induces an expansion of multifunctional NK cells which might significantly increase NK cell cytotoxicity.

\section{Discussion}

In the present study, we demonstrated that antiretroviral naïve HIV-1 infection has an impact on the ability of autologous NK cells to produce IFN- $\gamma$ upon exposure to P. falciparuminfected RBC. As previously reportedly $[18,19,21]$, human NK cells from healthy people are known to produce IFN- $\gamma$ after contact with iRBC. NK cells could also protect against malaria by lysing iRBC; however, during this study, NK cell activity was measured with the expression of IFN- $\gamma$ after exposure to iRBC. Here we show that NK cells in general respond to iRBC by producing IFN- $\gamma$. However, superior NK cell IFN- $\gamma$ production is observed with seronegative participants relative to antiretroviral naïve HIV-1 infection $(p<0.05)$. This clearly indicates that antiretroviral naïve HIV-1 infection impairs the ability of NK cells to respond to iRBC. On the other hand, NK cells cocultured with RBCs from Plasmodium species-negative participants also produced significantly higher levels of IFN $-\gamma$ relative to NK cells culture alone. NK cell IFN- $\gamma$ production after coculture with RBC from people with undetectable Plasmodium species ( $\mathrm{URBC}$ ) is probably due to the endemic nature of malaria in Cameroon where virtually everybody is repeatedly exposed to the malaria parasite. Perhaps the reduction on NK cells' IFN- $\gamma$ response observed in HIV-positive individuals may be due to the impairment of a specific NK cell receptor involved in the cell-cell contact with iRBC. As shown in a previous study [20], the requirement for cell-cell contact leading to NK cell activation by iRBC indicates the existence of a specific receptor-ligand interaction between the NK cell and IRBC, yet unknown NK cell membrane receptors recognize Hsp70 expressed on iRBC [20]. 
The reduction of NK cell IFN- $\gamma$ production observed in antiretroviral naïve HIV-1-infected people was closely related to HIV disease progression, as we observed an inverse correlation between IFN- $\gamma$ production and plasmatic VL. This is probably linked with an effective immune system as lower plasmatic VL $\left(<2 \log _{10}\right)$ usually correlates with the ability of individuals to control the virus. On the other hand, a high VL is an indication of unchecked expansion of the virus, probably arising from the depletion of the immune system by HIV-1. NK cells represent one of the first and important barriers against malaria [21]; alteration of their function in antiretroviral naïve HIV-1-infected people with respect to IFN- $\gamma$ production as demonstrated by this study may lead to a general impairment of NK cell-mediated innate immune response and as such also adaptive immunity. This impairment increases with HIV disease progression and exacerbates malaria infections in antiretroviral naïve HIV-1-infected people. In malaria intense regions, there is need to consider people living with HIV as being highly vulnerable to malaria and should therefore be offered prophylactic malaria treatment like in pregnant women and children [3].

The CD56 $6^{-}$CD16 ${ }^{+} \mathrm{NK}$ cell subset represents a minor NK cell population (Fig. 1d), but was significantly increased in HIV-positive participants. Even in the absence of a stimuli (here iRBC), we observed a significant increase in GB production in HIV-positive compared to HIVnegative participants (Fig. $5 \mathrm{e}$ ) in the $\mathrm{CD}^{-} 6^{-} / \mathrm{CD} 16^{+} \mathrm{NK}$ cell subset. In addition, HIV-positive participants displayed multifunctional $\mathrm{CD} 56^{-} / \mathrm{CD} 16^{+} \mathrm{NK}$ cell subset simultaneously expressing significant elevated levels of perforin, $\mathrm{GB}$, and CD107a $(p=0.03)$ in relation to HIVnegative participants. Perhaps antiretroviral naïve HIV infection induces the expansion of multifunctional NK cells simultaneously producing CD107a, perforin, and GB, which might significantly increase NK cell cytotoxicity as shown in previous studies [26, 27]. Thus, there is a need to evaluate antiretroviral naïve NK cell iRBC killing potential.

Differential expression levels of GB and perforin observed in NK cell subsets in the present study indicate differences in the functional properties of NK cell subpopulations.

\section{Conclusion}

NK cells from antiretroviral naïve people living in Cameroon demonstrated a significant impairment in IFN- $\gamma$ production when cocultured with P. falciparum-infected RBC. This reduction correlated inversely with HIV-1 plasmatic VL. Thus, antiretroviral naïve HIV-1 infection can dampen NK cell-mediated immunity to P. falciparum infection in malaria-intense regions. This could in effect escalate morbidity and mortality in people chronically infected with HIV-1.

\section{Acknowledgement}

We wish to thank CIRCB, EDTCP, Grand Challenge Canada, OWSD, SIDA, and TWAS for funding this work, and all the volunteers for sample donations.

\section{Statement of Ethics}

This study was approved by the National Ethical Committee of Cameroon with administrative authorization No. 2015/08/631/CE/CNERSH/SP. A signed informed consent was obtained from all participants. 


\section{Disclosure Statement}

The authors declare no conflict of interest. This work was supported by CIRCB. Carole Stéphanie Sake Ngane has received an OWSD/SIDA fellowship (3240274095), Godwin Nchinda has received an EDTCP Grant (TA.2010.40200.016), TWAS (12059RG/bio/af/ac_G), and Grand Challenge Canada Grant (0121-01), and Chae Gyu Park has received an African Korean Collaborative grant (NRF-2013K1A3A1A09076155).

\section{References}

1 World Health Organization: HIV/AIDS. 2015. http://www.who.int/mediacentre/factsheets/fs360/en/ (accessed September 14, 2016).

2 World Health Organization: World Malaria Report. 2015. http://who.int/malaria/publications/worldmalaria-report/report/en/ (accessed September 14, 2016).

-3 World Health Organization Malaria Policy Advisory Committee and Secretariat: Inaugural meeting of the malaria policy advisory committee to the WHO: conclusions and recommendations. Malaria J 2012;11:137.

-4 Grossman Z, Meier-Schellersheim M, Sousa AE, Victorino RM, Paul WE: CD4+ T-cell depletion in HIV infection: are we closer to understanding the cause? Nat Med 2002;8:319-323.

5 Sousa AE, Carneiro J, Meier-Schellersheim M, Grossman Z, Victorino RM: CD4 T cell depletion is linked directly to immune activation in the pathogenesis of HIV-1 and HIV-2 but only indirectly to the viral load. J Immunol 2002;169:3400-3406.

6 Appay V, Sauce D: Immune activation and inflammation in HIV-1 infection: causes and consequences. J Pathol 2008;214:231-241.

7 McMichael AJ, Borrow P, Tomaras GD, Goonetilleke N, Haynes BF: The immune response during acute HIV-1 infection: clues for vaccine development. Nat Rev Immunol 2010;10:11-23.

-8 Caligiuri MA: Human natural killer cells. Blood 2008;112:461-469.

$\checkmark 9$ Vivier E, Ugolini S: Natural killer cells: from basic research to treatments. Front Immunol 2011;2:18.

10 Vivier E, Raulet DH, Moretta A, Caligiuri MA, Zitvogel L, Lanier LL, et al: Innate or adaptive immunity? The example of natural killer cells. Science 2011;331:44-49.

11 Vivier E, Tomasello E, Baratin M, Walzer T, Ugolini S: Functions of natural killer cells. Nat Immunol 2008;9:503-510.

12 von Bubnoff D, Andres E, Hentges F, Bieber T, Michel T, Zimmer J: Natural killer cells in atopic and autoimmune diseases of the skin. J Allergy Clin Immunol 2010;125:60-68.

13 Geller MA, Miller JS: Use of allogeneic NK cells for cancer immunotherapy. Immunotherapy 2011;3:1445-1459.

14 Fauriat C, Long EO, Ljunggren HG, Bryceson YT: Regulation of human NK-cell cytokine and chemokine production by target cell recognition. Blood 2010;115:2167-2176.

-15 Lünemann A, Lünemann JD, Münz C: Regulatory NK-cell functions in inflammation and autoimmunity. Mol Med 2009;15:352-358.

16 Ljunggren HG, Malmberg KJ: Prospects for the use of NK cells in immunotherapy of human cancer. Nat Rev Immunol 2007; 7:329-339.

17 Bayigga L, Nabatanzi R, Sekiziyivu PN, Mayanja-Kizza H, Kamya MR, Kambugu A, et al: High CD56++CD16natural killer (NK) cells among suboptimal immune responders after four years of suppressive antiretroviral therapy in an African adult HIV treatment cohort. BMC Immunol 2014;15:2.

18 Artavanis-Tsakonas K, Riley EM: Innate immune response to malaria: rapid induction of IFN-gamma from human NK cells by live Plasmodium falciparum-infected erythrocytes. J Immunol 2002;169:2956-2963.

19 Korbel DS, Newman KC, Almeida CR, Davis DM, Riley EM: Heterogeneous human NK cell responses to Plasmodium falciparum-infected erythrocytes. J Immunol 2005;175:7466-7473.

20 Bottger E, Multhoff G, Kun JF, Esen M: Plasmodium falciparum-infected erythrocytes induce granzyme B by NK cells through expression of host-Hsp70. PloS One 2012;7:e33774.

-21 Chen Q, Amaladoss A, Ye W, Liu M, Dummler S, Kong F, et al: Human natural killer cells control Plasmodium falciparum infection by eliminating infected red blood cells. Proc Natl Acad Sci USA 2014;111:1479-1484.

22 Roland J, Soulard V, Sellier C, Drapier AM, Di Santo JP, Cazenave PA, et al: NK cell responses to Plasmodium infection and control of intrahepatic parasite development. J Immunol 2006;177:1229-1239.

23 Trager W, Jensen JB: Human malaria parasites in continuous culture. 1976. J Parasitol 2005;91:484-486.

24 Trager W, Jensen JB: Continuous culture of Plasmodium falciparum: its impact on malaria research. Int J Parasitol 1997;27:989-1006.

-25 Fernandez V, Treutiger CJ, Nash GB, Wahlgren M: Multiple adhesive phenotypes linked to rosetting binding of erythrocytes in Plasmodium falciparum malaria. Infect Immun 1998;66:2969-2975.

-26 Mavoungou E, Held J, Mewono L, Kremsner PG: A Duffy binding-like domain is involved in the NKp30-mediated recognition of Plasmodium falciparum-parasitized erythrocytes by natural killer cells. J Infect Dis 2007;195: 1521-1531.

27 Pardo J, Aguilo JI, Anel A, Martin P, Joeckel L, Borner C, et al: The biology of cytotoxic cell granule exocytosis pathway: granzymes have evolved to induce cell death and inflammation. Microbes Infect 2009;11:452-459. 